\title{
Desvelando invisibilidades en el ámbito de la cognición situada. La formación inicial del profesorado en Educación Artística
}

\author{
Desvelar a invisibilidade no campo da cognição situada. Formação Inicial de Professores em \\ Arte-Educação \\ Unveiling invisibilities in the field of situated cognition. Initial Teacher Training in Art Education
}

\author{
Ma Amparo Alonso Sanz \\ amparo.alonso@ua.es \\ Universidad de Alicante
}

\section{RESUMEN}

Mediante la presente investigación se pretende contribuir a la mejora de la formación inicial del profesorado en Educación Artística. Para ello a través de la metodología de Investigación Educativa Basada en las Artes se desvelan las invisibilidades que se producen en el ámbito de la cognición situada. Mediante el uso de la fotografía y fragmentos de texto asociados a las imágenes nos acercaremos a tres ejes principales que se desarrollan en las aulas universitarias: actividades artísticas; relaciones interpersonales; situaciones, entornos y ambientes.

Palabras clave: Investigación Educativa Basada en las Artes, cognición situada

\section{RESUMO}

Com a presente investigação pretende-se contribuir para uma melhor formação inicial dos professores de Educação Artística. Para isso através da metodologia de Investigação Educativa Baseada nas Artes se revelam as invisibilidades que ocorrem na zona da cognição situada. Mediante o uso da fotografia e partes de textos associados as imagens, aproximamo-nos de três eixos principais que se desenvolvem nas universidades: atividades artísticas; relações interpessoais; situações, circunvizinhanças e ambientes.

Palavras-chave: Investigação Educativa Baseada nas Artes, cognição situada

\section{ABSTRACT}

This research aims to contribute to the improvement of initial teacher training in Art Education. For this purpose Arts-Based Educational Research methodology is used to unveil invisibilities that occur in the field of situated cognition. We will approach to three main themes that are developed in the university classrooms by using photography and also by using text fragments associated with pictures. Those themes are: artistic activities, interpersonal relationships, situations and environments.

Key words: Arts-Based Educational Research, situated cognition. 

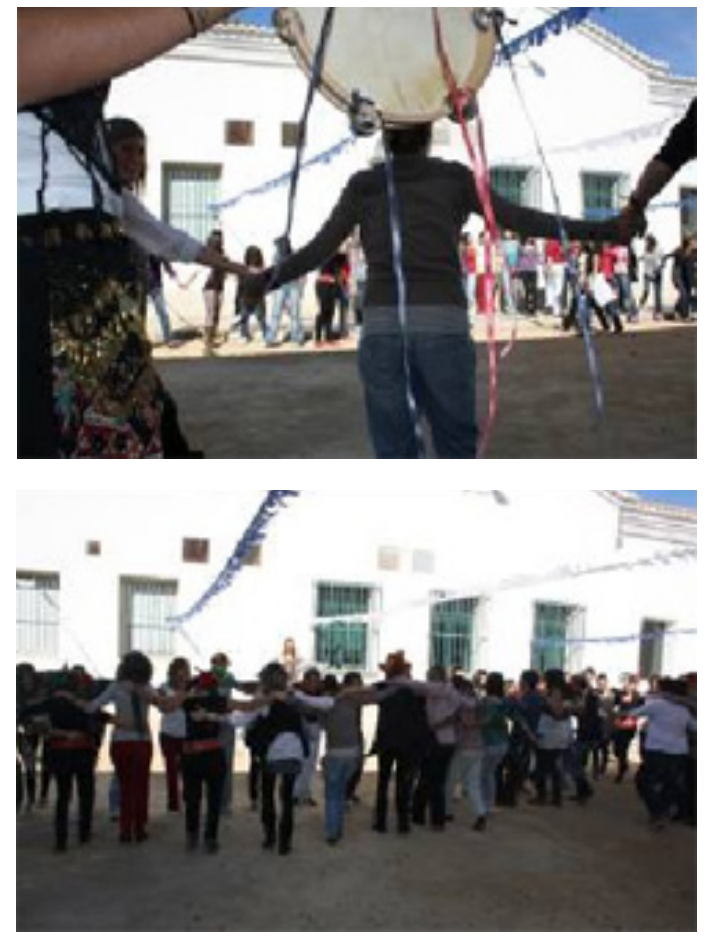

Figura 1. Foto-resumen. Alumnas danzando como introducción a una dinámica grupal. Te toco, me atrevo, os cojo, te acerco, me a-CERCO

\section{INTRODUCCIÓN}

Mediante la presente investigación se pretende contribuir a la mejora de la formación inicial del profesorado en Educación Artística, desvelando las invisibilidades que se producen en el ámbito de la cognición situada.

Es preciso argumentar, desde un punto de vista internacional y nacional, las razones que nos hacen pensar que la temática escogida resulta pertinente y de interés en el desarrollo del conocimiento didáctico del arte.

En 2004, Eisner propone cuál es la investigación necesaria en la Educación Artística. Entre otras dimensiones propone la necesidad de estudios dedicados a la enseñanza y el aprendizaje en el campo de la Educación Artística (por ser necesarios para mejorar la práctica docente al descubrir las virtudes y también los defectos de los enseñantes de arte). Especificando que éstos debieran tener una concepción am

\footnotetext{
1 NOTA: Las leyendas incluidas a pie de imagen incorporan dos textos. En primer lugar un contenido descriptivo (en negrita). $Y$ a continuación otro que es parte de la forma de la imagen, del sentido unívoco que entre lector y autora le damos a estas fotografías, en ocasiones como juego de palabras, en otros como anécdotas, reflexiones, rimas o recuerdos.
}

plia y generosa que incluyese: [1] Qué hacen los enseñantes profesionales de arte cuando enseñan y cuáles son las consecuencias. [2] Qué hacen los alumnos para influirse mutuamente. [3] Qué ha enseñado la situación, los aspectos del diseño del entorno y sus dimensiones sociales.

Por otro lado, mientras que hace 15 años las investigaciones en Educación Artística giraban en torno al tema del currículo, desde hace 6 años el interés se ha desplazado entre otros campos de estudio hacia el conocimiento práctico, la investigación-acción, la investigación en el aula, e incluso, la formación del profesorado (Agra, 2005).

\section{DESARROLLO}

El estudio fue realizado con alumnos de Magisterio durante el curso académico 2009-2010, en la Facultad de Educación de la Universidad de Alicante, en España.

La recogida de datos se llevó a cabo entre los meses de noviembre y diciembre de 2009.

Esta investigación se dirige a los profesores de universidad, especialmente a los formadores en Educación Artística.

La investigación se elaboró bajo la responsabilidad de la profesora autora de este artículo y gracias a la colaboración de los 206 alumnos matriculados en la asignatura obligatoria de Expresión Plástica del título de Maestro de la especialidad de Educación Infantil durante el curso académico 2009-2010. Siendo la entidad de acogida de la investigación la Universidad de Alicante.

\section{OBJETIVOS}

Este trabajo de investigación es un extracto de una tesis doctoral que ha tenido como propósito contribuir a la mejora de la formación del alumnado de Magisterio en Educación Artística, a partir del conocimiento de las historias de vida de futuros maestros respecto a esta materia y de las implicaciones educativas derivadas de la investigación. Abordada la tesis desde una metodología de investigación plural incluía: una narrativa autobiográfica, investigación cualitativa a través de narrativas obtenidas de entrevistas semiestructuradas; investigación cuantitativa a través de cuestionarios de respuesta cerrada; e investigación basada 
en el Arte a partir de fotografías. En este artículo ofreceremos únicamente esta última porción.

El análisis de las historias de vida de alumnado de Magisterio, desarrollado en la tesis, se centra en las experiencias en Educación Artística que han tenido lugar tanto en la educación reglada como informal, desde la infancia hasta su formación inicial en la universidad. Desde la IEBA se ha pretendido abordar como cuestión de investigación especialmente la educación reglada en este último periodo de aprendizaje artístico de los estudiantes de Magisterio.

El interés de la siguiente investigación radica en la necesidad de responder adecuadamente a las reformas educativas desde una efectiva formación inicial del profesorado, activando una actitud crítica y en consonancia a las necesidades estudiantiles.

Los objetivos específicos desde este trabajo de investigación son:

- Visibilizar qué hacen los profesores de arte cuando enseñan en la Universidad, qué ocurre en las aulas.

- Visibilizar qué influencias se producen entre el alumnado en las relaciones interpersonales.

- Visibilizar las situaciones, aspectos del diseño del entorno y las dimensiones sociales propias de los ambientes, entornos y contextos en los que se puede producir el aprendizaje situado.

\section{METOdOLOGÍA}

La metodología aplicada es la Investigación Educativa Basada en las Artes. Se hace uso de la fotografía para el registro y análisis de datos, y para la exposición de resultados se acompaña la fotografía de fragmentos reducidos de texto con una fuerte carga emotiva por lo que no es puramente una forma no-lingüística.

La toma de fotografías se realizó durante el transcurso de las últimas semanas de clase y únicamente en aquellas sesiones prácticas que lo permitieron por su diseño, por consistir el papel de la profesora en mantenerse como apoyo, referente o acompañante del trabajo que desempeñaban el alumnado de forma autónoma. De esta forma se contaba con la libertad de movimientos y de tiempo para estar pendiente de la fotografía a la vez que de la evaluación de las tareas del alumnado, sin dejar de lado las responsabilidades docentes.

Después de las sesiones de fotografía se descargaban en el ordenador los archivos de imagen rápidamente. Esto permitía refrescar la memoria, revivir las experiencias, escuchar mentalmente de nuevo el sonido de cuánto había dicho el alumnado, a modo de cuaderno de campo.

Posteriormente se realizó una selección de fotografías, bajo el criterio de cumplimiento de las mejores condiciones estéticas y evocativas. Se conformó la presentación de las imágenes agrupadas por contenidos y conforme a requisitos comunicativos que se acentuasen por lectura de unas fotografías junto a otras, considerando líneas compositivas, tonos, estructura... Tres profesoras del área de Expresión Plástica con las que se comparte docencia contribuyeron en el desempeño de estas tareas, de manera que se produjo la triangulación necesaria para la obtención de las voces de otros investigadores expertos en la discriminación, clasificación y maquetación de las imágenes.

Finalmente se acompañaron de textos contextuales a pie de imagen, producto de una postura reflexiva tanto en la fase de fotografiado como en la de volcado al ordenador y seleccionado. Las leyendas incorporadas a pie de fotografía son parte de su forma, del sentido unívoco que entre lector y autora le damos a estas fotografías. En este caso el texto puede que se haya usado para:

- Reducir las posibilidades significativas de la imagen (función de anclaje)

- Complementar la imagen conformando una unidad sígnica (función de relevo)

- Ofrecer un significado distinto al del propio registro fotográfico.

Cuando pensamos en Ia IBA suele hacerse considerando la utilización de las imágenes o representaciones artísticas visuales y performativas como elemento esencial de la representación de las experiencias de los sujetos. Sin embargo, el componente estético no se refiere sólo a estas representaciones visuales. 
También se vincula a la utilización de textos que permitan, debido al formato elegido -literario, poético, ficcional-, conseguir el propósito heurístico que esta perspectiva posibilita. Textos que permitan a los lectores plantearse cuestiones relevantes y mirarse en ellos a modo de espejo que les interroga.

(Hernández, 2008, p. 95)

Se satisfacen los requisitos establecidos por Eisner \& Barone (2006) para esta metodología: los propósitos de esta investigación se encuentran asociados a la actividad artística y resultan de carácter educativo, y se presentan con presencia de cualidades estéticas o elementos de diseño que impregnan el proceso de investigación y sus textos.

\section{RESULTADOS}

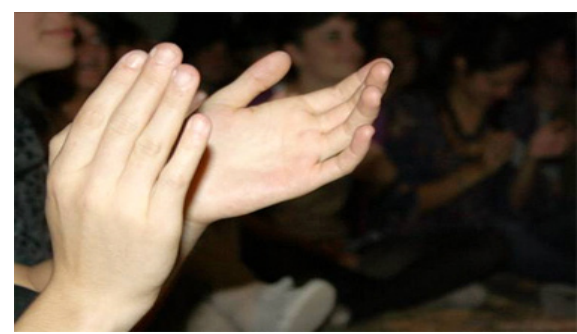

Figura 2. Aplauso en una exposición de trabajos por parte de los compañeros de clase. ¿Cómo no reconocer el reconocimiento?
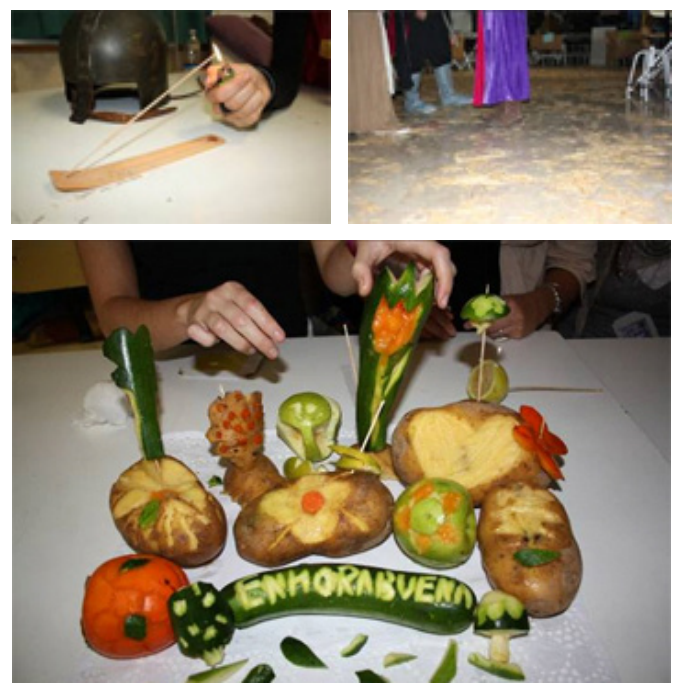

Figura 3. Estimulación de todos los sentidos en clase de talla, ambientada en la época medieval. Sentí que no iban a olvidar el sabor de la victoria, la campana de la bruja el olor a paja, incienso, frutas y hortalizas, la humedad en las manos, el color en la retina.

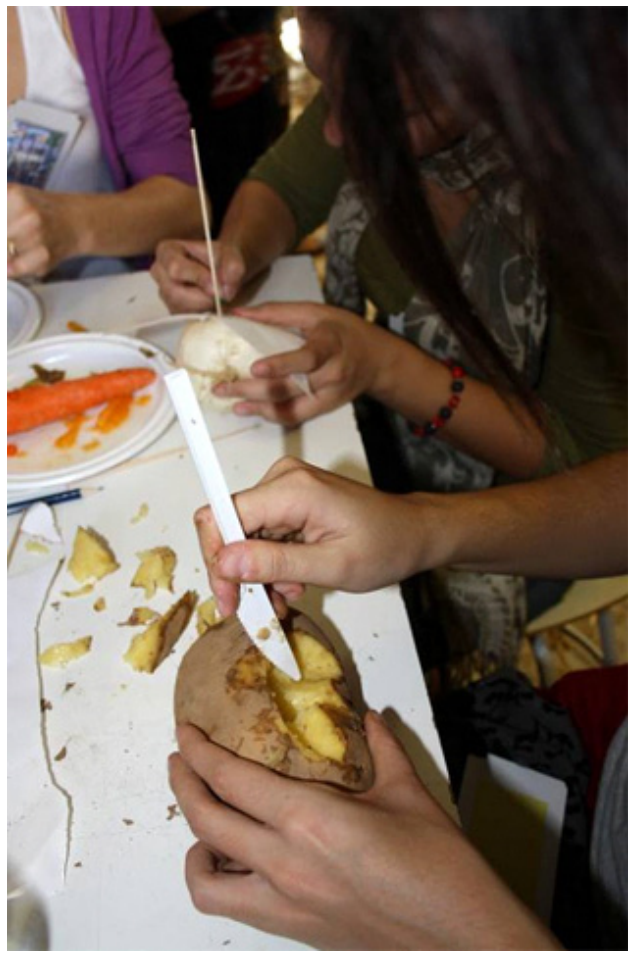

Figura 4. Talla en frutas, hortalizas y vegetales con instrumentos usables por niños. ¿Me recuerdas?, me preguntó en tutorías. Y entonces añadió: yo acompañé a curarse a la compañera que se cortó aquel día en clase.

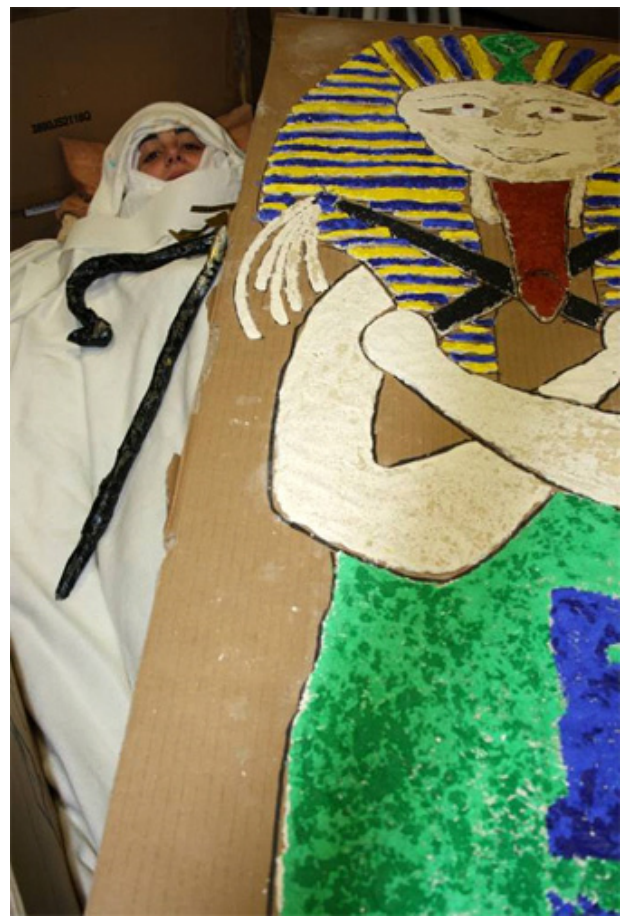

Figura 5. La clase ambientada en Egipto por los estudiantes para una práctica grupal. Yo sabía que la momia estaba escondida. Al acabar la clase y abrirse el sarcófago, me asusté igual que ellos. Que mejor final que la sorpresa y la risa. 


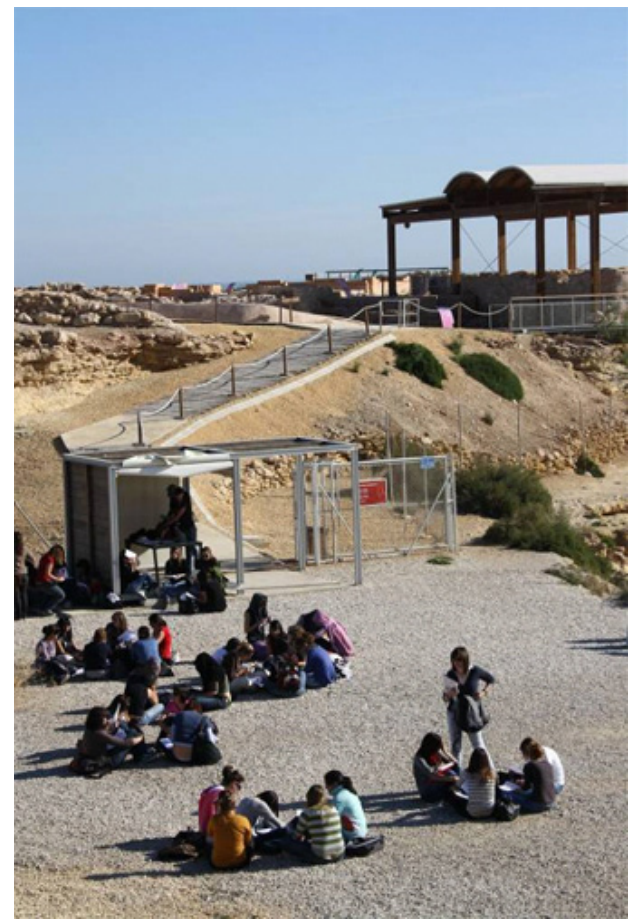

Figura 6. Dinámica tipo puzle como actividad de aprendizaje basada en un Proyecto sobre el patrimonio. Yacimiento íbero de la Illeta dels Banyets en El Campello. Yacer junto al yacimiento, ya cimientos de nuevos conocimientos. Cimientos de nuevos conocimientos.

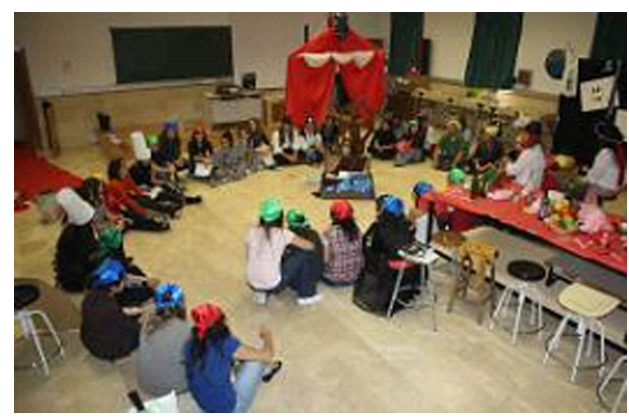

Figura 7. Estudiantes y profesora en asamblea en el suelo de clase. Los tableros de juego te obligan a mover ficha.

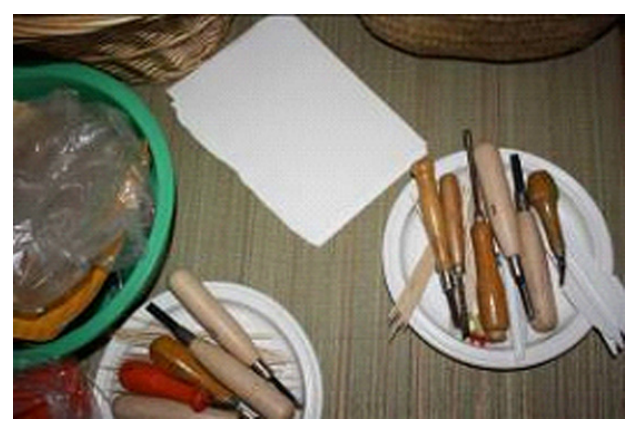

Figura 8. Preparación, clasificación y cuidado del material por parte de los estudiantes. Era sorprendente ver con qué cuidado paseaban entre las mesas repartiendo el material a los compañeros.

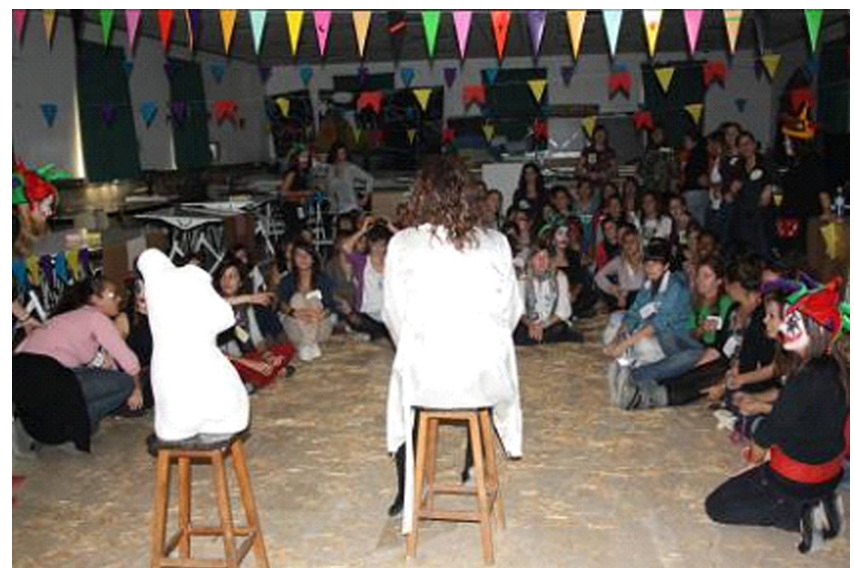

Figura 9. Dinámica grupal donde un tercio de la clase prepara la práctica para el resto. A ella todavía le costará entender que cuando creyó posteriormente que plagiaban el trabajo de su equipo, el resto de compañeros no hacían sino reconocer cuánto les habían enseñado ellos a toda la clase. A ella todavía le costará ceder, dejar participar a los demás, no tomar la iniciativa siempre, callar cuando sabe la respuesta, no demostrar continuamente que está preparada, prestar responsabilidades. Pero confío en que como yo, aprenderá a competir únicamente contra ella misma y a tomar por logros propios los de sus alumnos y amigos.

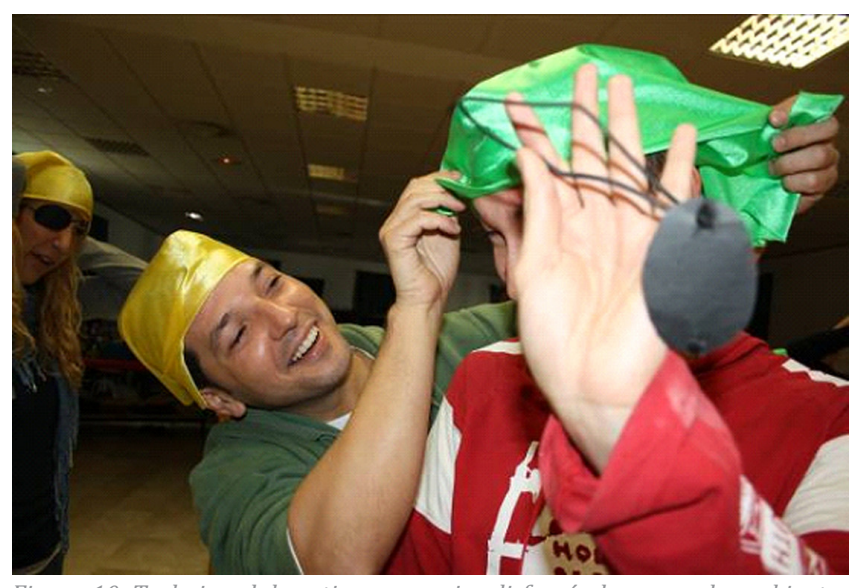

Figura 10. Trabajo colaborativo en parejas disfrazándose para la ambientación del ejercicio. Como en Barrio Sésamo: "Sólo no puedes, con amigos sí".

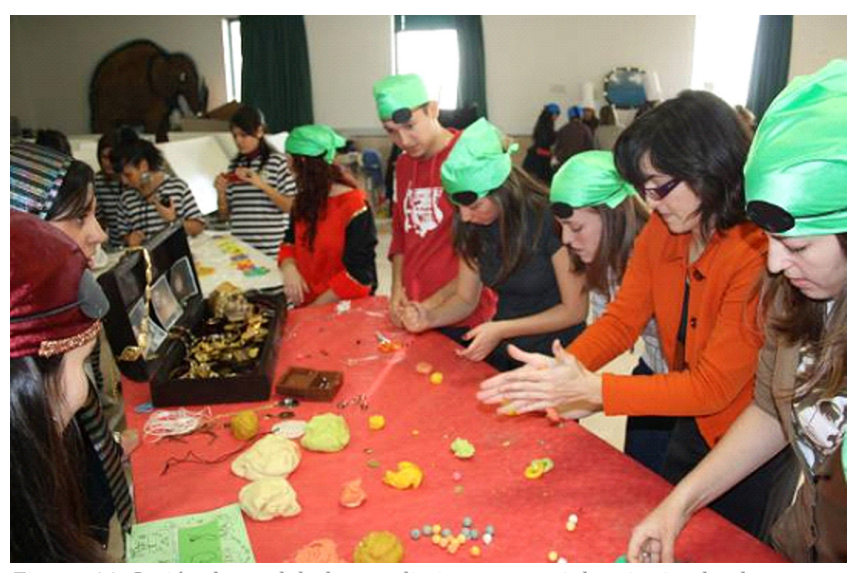

Figura 11. Sesión de modelado con distintos materiales siguiendo el paso por rincones rotatorios. Después de 15 años de amistad con Bibiana tuve que cederle la cámara y reconocerle que tenía razón, que estaba deseando modelar con mis alumnos, entre ellos y como ellos dijeran. 

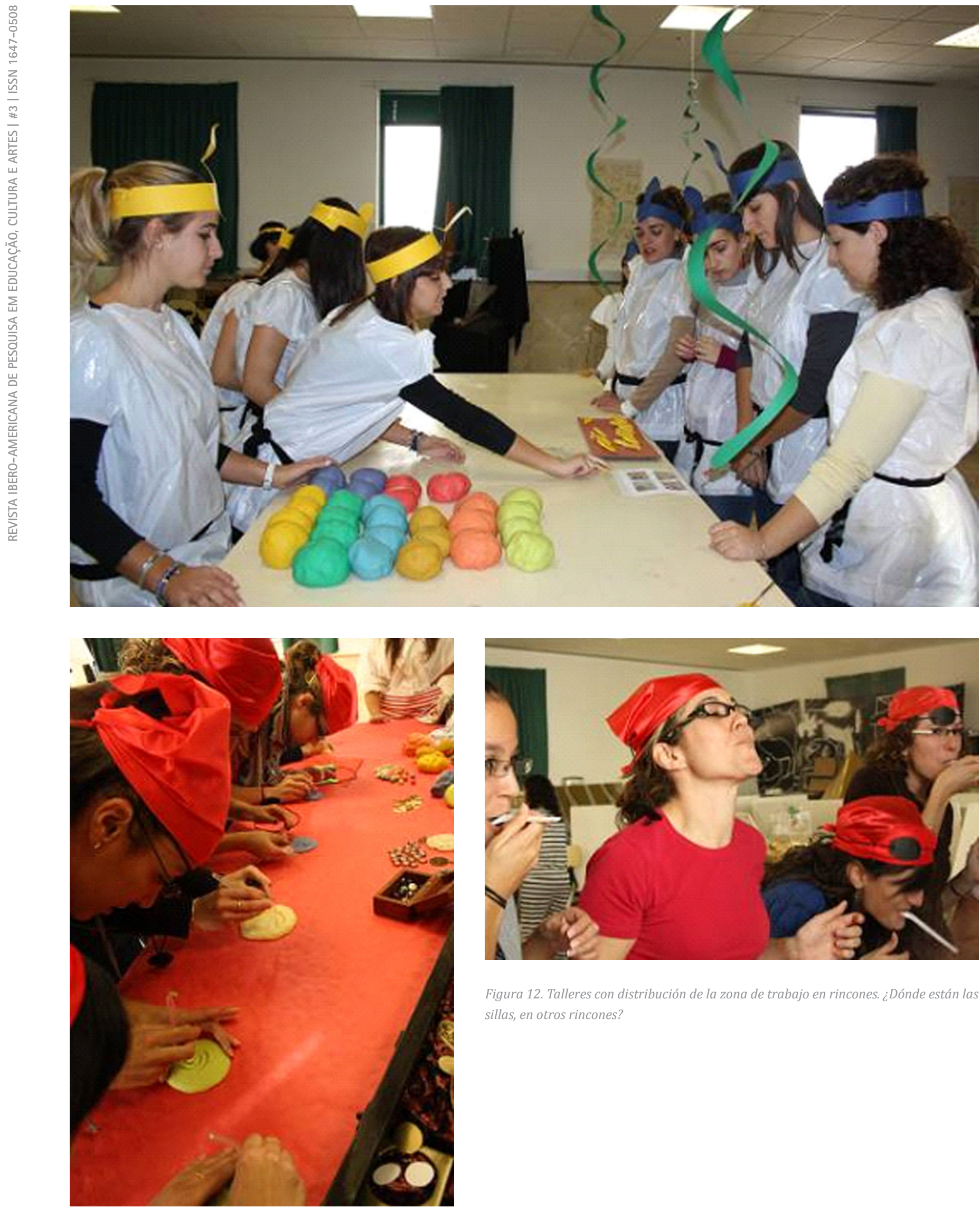

Figura 12. Talleres con distribución de la zona de trabajo en rincones. ¿Dónde están las sillas, en otros rincones? 

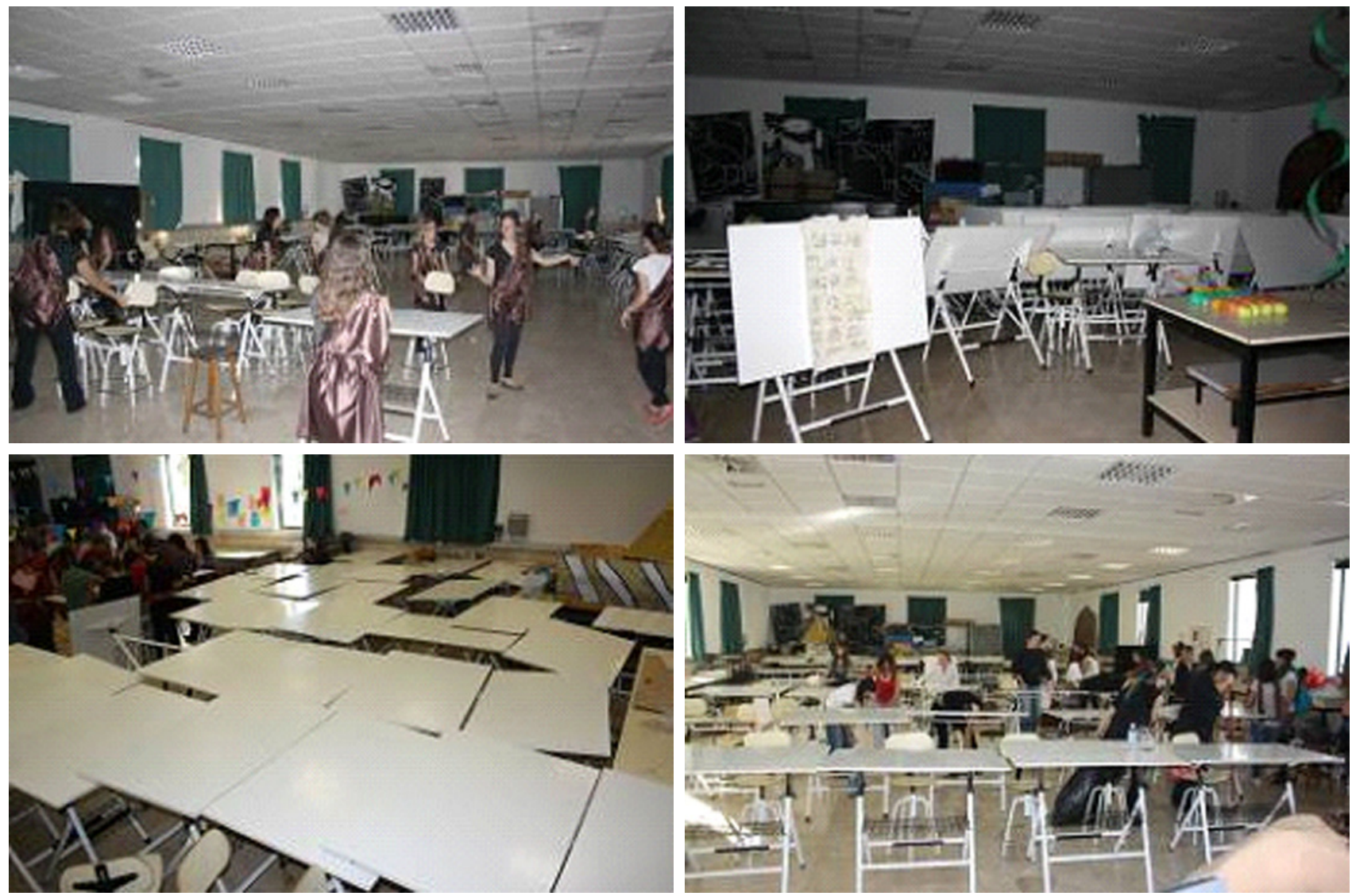

Figura 13. Estudiantes desplazando mesas para organizar el aula. El primer día cerré la puerta hasta que recogieron, nunca más les cerré la puerta, pero no sé si podrán perdonarme esa falta de confianza inicial.

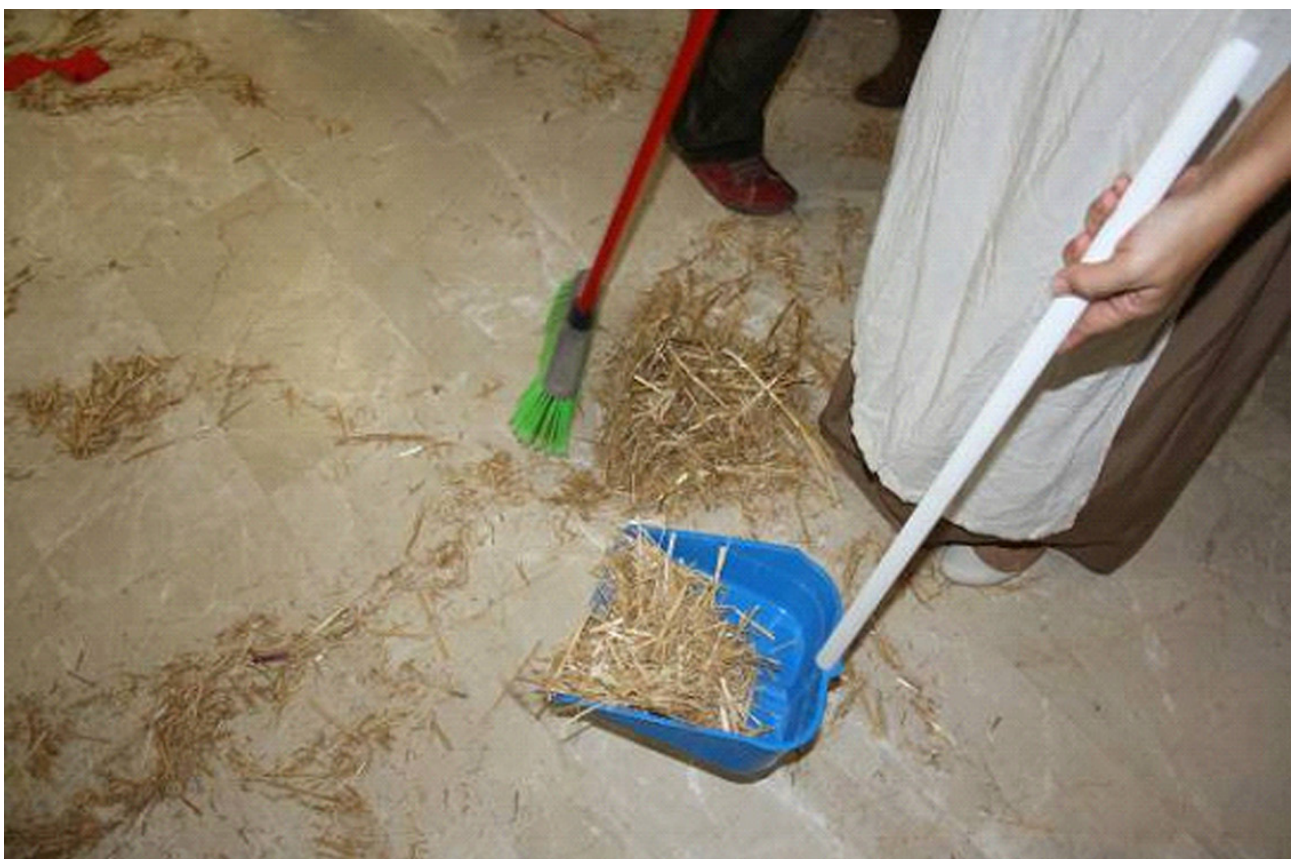

Figura 14. Alumna limpiando el aula al finalizar las actividades. No es más limpio el que más limpia, sino el que menos ensucia. 

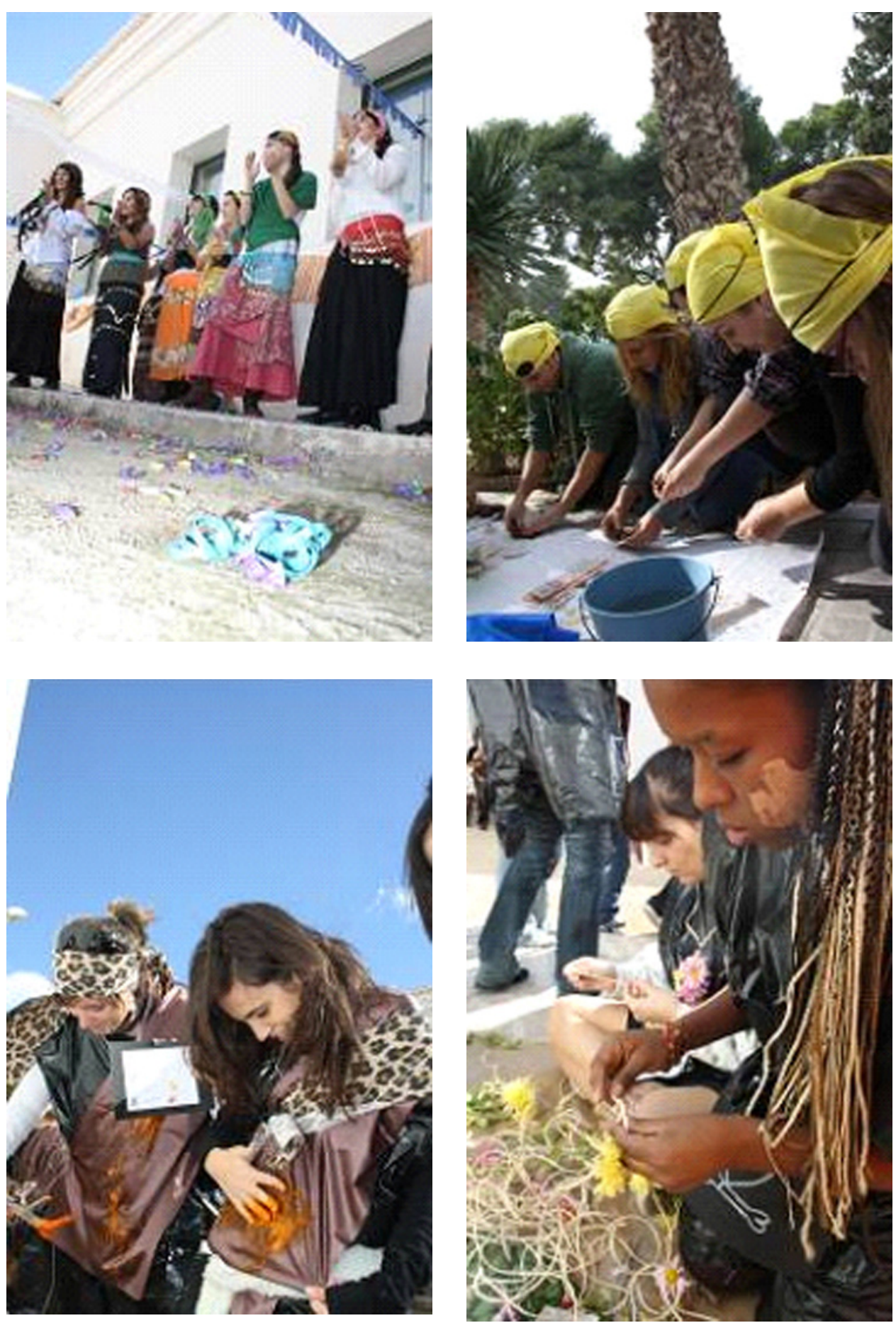

Figura 15. Sesiones al exterior del aula en el Campus de la Universidad. Aunque no miren, para ellos nunca eres invisible. 


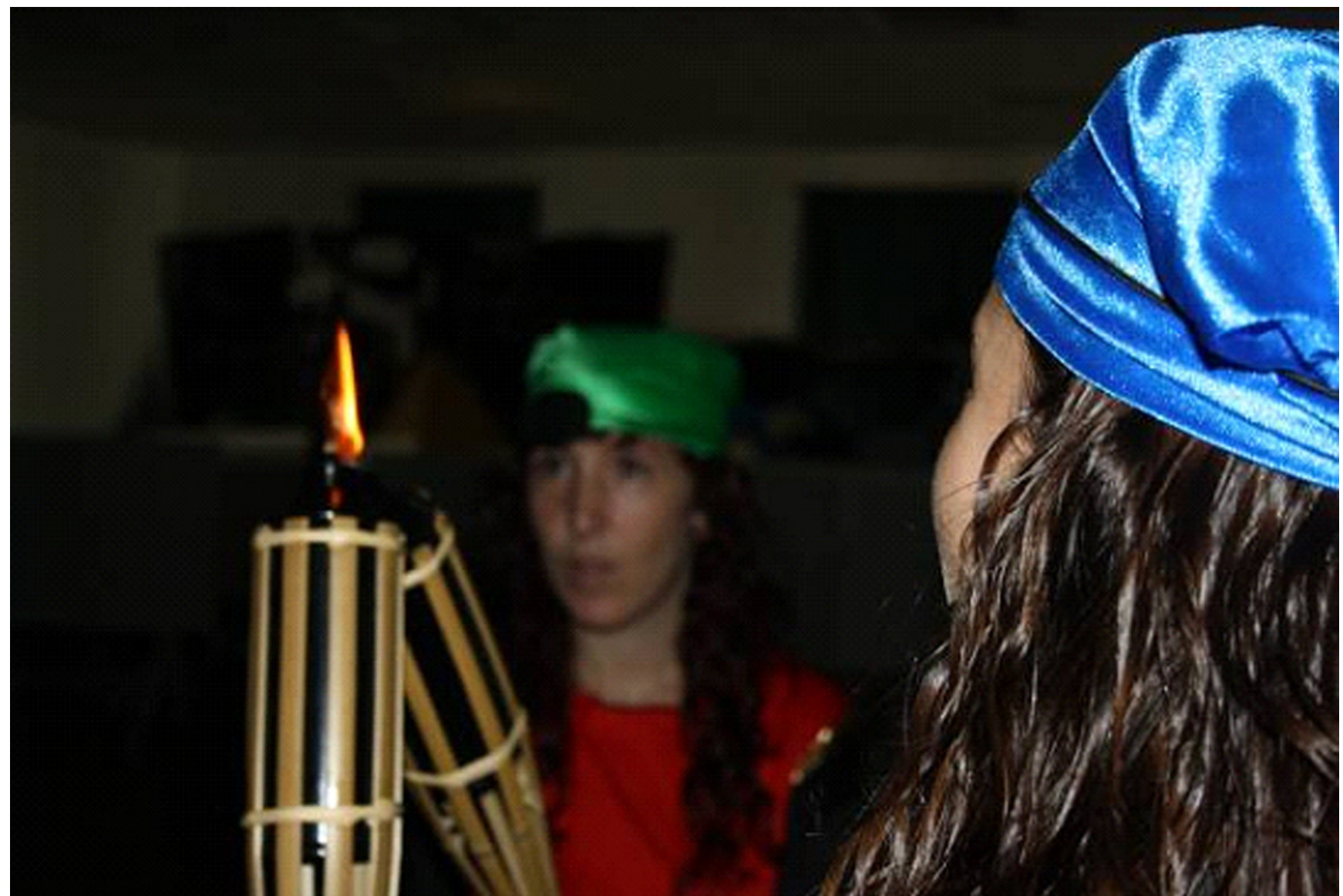

Figura 16. Clase a oscuras con iluminación de antorchas. Relájate maestra, no va a pasar nada, llevaremos cuidado, nada va arder, y sabemos dónde están los extintores. Terapia, mi terapia, mis sanadores.
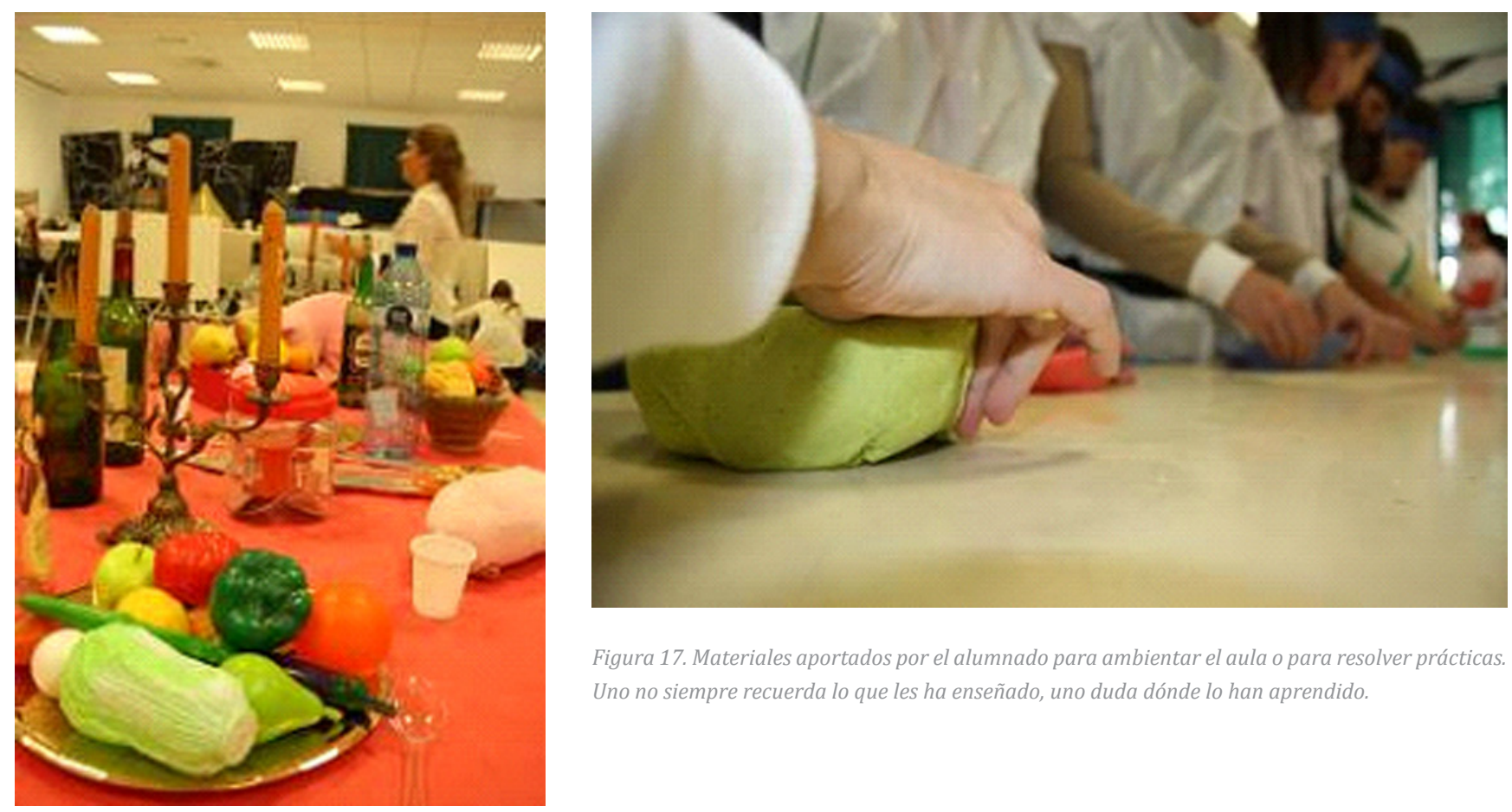

Figura 17. Materiales aportados por el alumnado para ambientar el aula o para resolver prácticas. Uno no siempre recuerda lo que les ha enseñado, uno duda dónde lo han aprendido. 

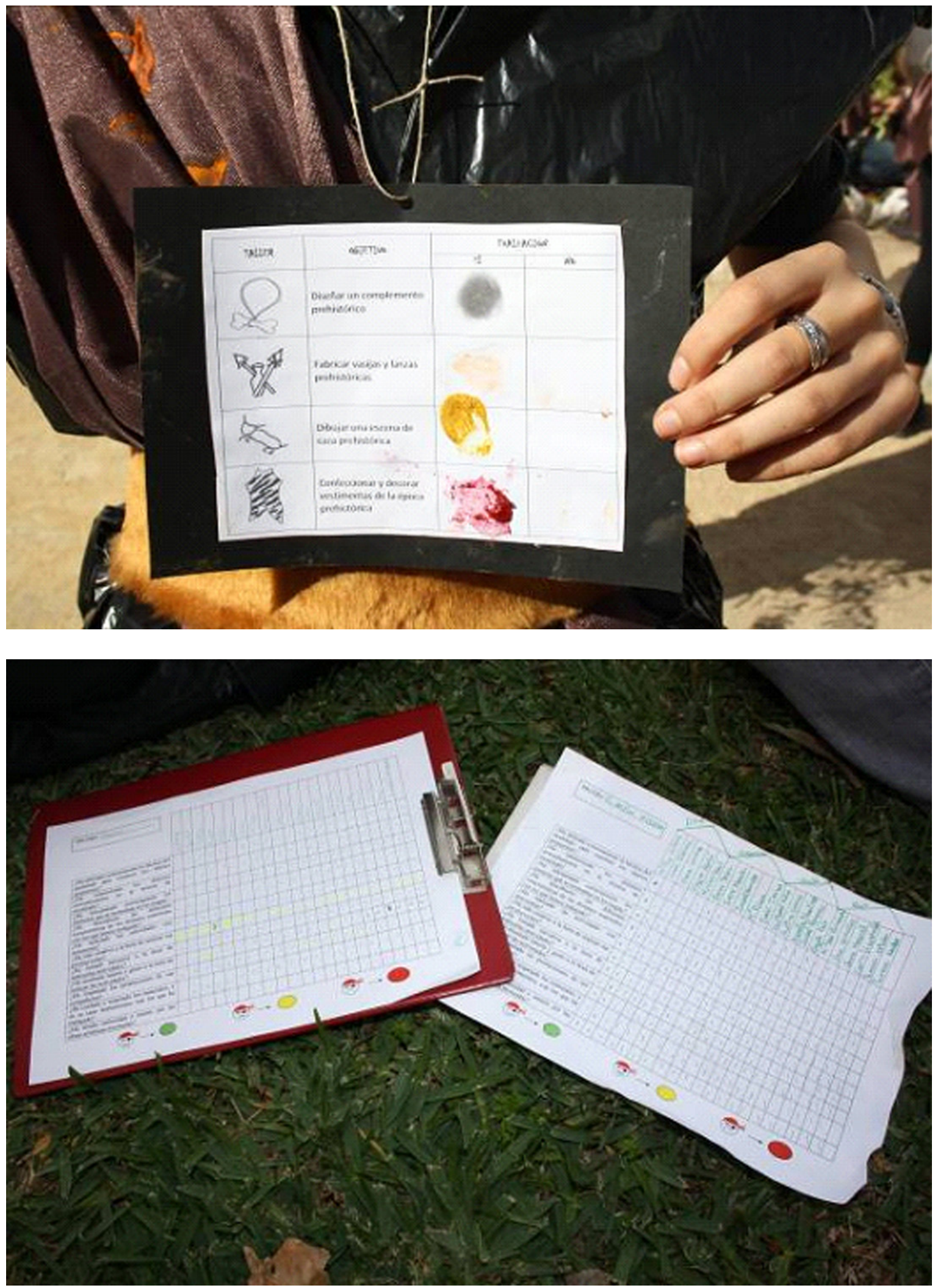

Figura 18. Plantillas de coevaluación diseñadas por el alumnado. Tal vez recuerden cuando sean maestras que existen otros modos de evaluación no numéricos: táctiles, olorosos, visuales. 
Al hacerse públicos algunos momentos increíblemente "pedagógicos" que se han compartido entre alumnado y docente, la instantánea se torna forma de retentiva, memoria, recuerdo, como manera de congelar tiempos llenos de belleza y emotividad transmitidos de forma estética al espectador. La toma de fotografías fue reconocida por el alumnado positivamente e incluso con admiración, por considerar que el docente se aproximaba a detalles con cariño, que se mezclaba entre ellos para captar lo interesante, fue acogida como una valoración de su propio trabajo, como una manifestación no verbal del afecto del profesor. Fue interesante comprobar que solicitaban esas imágenes, que deseaban conservarlas, que para ellos esas fotografías eran el recuerdo de su formación inicial como futuros profesores de la Educación Artística. Estos hechos, justifican que el consentimiento informado de los participantes para usar las fotografías en este trabajo fuera inmediato y total.

Estas fotografías, junto con el juego tipográfico que las acompaña a pie de página, constituyen otra forma de lenguaje no textual de comunicar resultados al final de un proceso. "Si lo que se va a presentar al final del proceso de investigación son series de fotografías en blanco y negro, tendremos que estar mucho más atentos a la luz que hay en el aula" (Marín, 2005, p. 252).

\section{REVISIÓN DE LA INVESTIGACIÓN. APLICACIÓN DE LOS CRITERIOS DE EVALUACIÓN DE LA INVESTIGACIÓN EDUCATIVA BASADA EN EL ARTE}

Seguiremos en este apartado como orientación cuatro criterios para valorar la ABER, Arts-Based Educational Research, que plantean los autores Eisner y Barone (2006) no como fórmulas si no para ser considerados en mayor o menor grado y sin necesidad de estar todos presentes en una misma investigación, que trataré de resumir a continuación. Teniendo además como premisa que estos mismos investigadores sugieren que la competencia para evaluar también se requiere de aquellos que son jueces de una porción de la ABER. La competencia se refiere a un nivel de discernimiento que no todos los individuos poseen: El reconocimiento de las grandes (o simplemente buenas) obras de arte requiere de grandes (o buenas) audiencias. Y esto no es menos cierto para la Investigación Educativa Basada en las Artes.

En primer lugar la posibilidad de que el trabajo sea juzgado por su efecto de iluminación o capacidad para revelar lo que no se apreciaba de otro modo, aumentando el conocimiento del mundo de la educación en la dirección planteada por el investigador.

En segundo lugar la investigación debe ser juzgada también por su generatividad -su capacidad para promover preguntas-. Una de las funciones más importantes de ABER es que plantea más preguntas que respuestas.

Un tercer aspecto que se puede utilizar para evaluar la investigación basada en las artes es su agudeza, es decir, en su capacidad para centrarse estrictamente en las cuestiones educacionales más destacadas.

Otra característica de la investigación basada en las artes es la generalización, es decir, su importancia respecto al fenómeno estudiado fuera del texto de la investigación.

El efecto iluminador ha residido en desvelar las invisibilidades entorno al ámbito de la cognición situada en Educación Artística tal y como nos planteábamos en los objetivos. Otra ventaja iluminadora es la función vicarial que en este caso han cumplido las fotografías, "vale más una imagen que mil palabras".

La generatividad de interrogantes se produce entorno a tres ejes principales que dan respuesta a los objetivos: qué actividades artísticas se desarrollan en las aulas universitarias; relaciones interpersonales; situaciones, entornos y ambientes.

La agudeza de esta investigación reside en que desvela factores relevantes para la cognición situada en Educación Artística, pero también determinantes para otras materias.

La generalización podría ser mayor si reuniese imágenes de las clases impartidas por otros profesores, pero esto se dejará como parte de posibles futuras investigaciones. Es en cualquier caso generalizable a otros cursos venideros que viendo las fotografías puedan hacer una lectura rápida de cómo pueden ser las clases e imaginar el tipo de relación 
que se llega a establecer entre compañeros e incluso con el profesor en las asignaturas de Educación Artística.

\section{CONCLUSIONES}

La Investigación Educativa Basada en las Artes nos ha permitido centrarnos en las experiencias en Educación Artística que han tenido lugar en la educación reglada durante la formación inicial del profesorado en la universidad, como parte de las historias de vida del alumnado de Magisterio. Visibilizando mediante fotografías aspectos de interés para la mejora de la preparación de maestros relacionados con:

- Lo que ocurre en las aulas. Tipos de contenidos, sistemas de evaluación, procedimientos, procesos inducidos por los profesores de arte; observables en las fotografías en los materiales, técnicas, herramientas, plantillas de evaluación, disfraces...

- Las relaciones interpersonales. Influencias entre el alumnado durante el trabajo cooperativo, colaborativo, individual...; registrados en las imágenes en las actitudes corporales, el lenguaje gestual, las expresiones faciales, la disposición espacial entre individuos, los distintivos grupales...

- Los aspectos situacionales. Aspectos del entorno perceptibles en los espacios interiores y exteriores escogidos, la iluminación, la disposición del mobiliario de las aulas, la decoración y ambientación de cada contexto.

Las implicaciones educativas de la investigación respecto al marco de la Educación Artística se ofrecen mediante una "teoría práctica VISUAL", recomendaciones gráficas y no textuales para orientarnos sobre qué hacer, un conjunto de principios y consejos materializados en imágenes encaminados a guiar a quienes están comprometidos en actividades educativas relacionadas con el Arte.

Estas imágenes podrían plantear nuevas formas de ver la Educación Artística en la universidad, como un proceso en perpetua construcción, como un ejercicio complejo e intrincado de posibilidades interpersonales, horizontales, colaborativas y cooperativas, rodeadas de una energía lúdica y de goce estético. Una materia que dependería de todos.
Esta selección de instantáneas recogerían un nuevo planteamiento si son re-utilizadas. Si se ofreciesen, al inicio de curso en la presentación de la asignatura, a nuevas generaciones de estudiantes. ¿Podrían servir de punto de partida, de ejemplo no verbalizado, de listón a superar, de ruptura de prejuicios, de ilustración de lo que se puede construir entre todos? ¿Servirían para favorecer acciones educativas innovadoras en el área artística tal y como se planteaba en el objetivo de esta investigación?

Y en último lugar nos harían recapacitar sobre la necesidad de explorar "otras aulas", de fotografiar otras prácticas o ejercicios de profesores que pudieran invitarnos a estar junto a ellos. La visibilización buscada en los objetivos de esta investigación abriría el debate a la comunidad científica, abriría la posibilidad de juzgar las enseñanzas, relaciones y ambientes mostrados, y permitiría proponer otras alternativas.

Sería necesaria más investigación que abarcase una comparativa no diferenciadora, más bien sumativa de posibilidades, una recopilación de aquellos ambientes deseados en Educación Artística que no a todos los profesores se nos hubiese ocurrido generar, en este sentido esta investigación podría resultar generalizable. Sería interesante almacenar un catálogo de fotografías que nos pudiese invitar con amabilidad a reproducir ambientes, escenas, escenarios, alternativas. En cualquier caso este catálogo debería estar vinculado a las propias narrativas de los profesores, en la medida en que escoger un día concreto de todo un curso para ser fotografiado no tendría por qué ser lo más representativo del conjunto de una docencia. Esta idea de catálogo que ha surgido a partir de esta Investigación Educativa Basada en el Arte podría ser objeto de futuras investigaciones que complementasen las visiones ya obtenidas. 

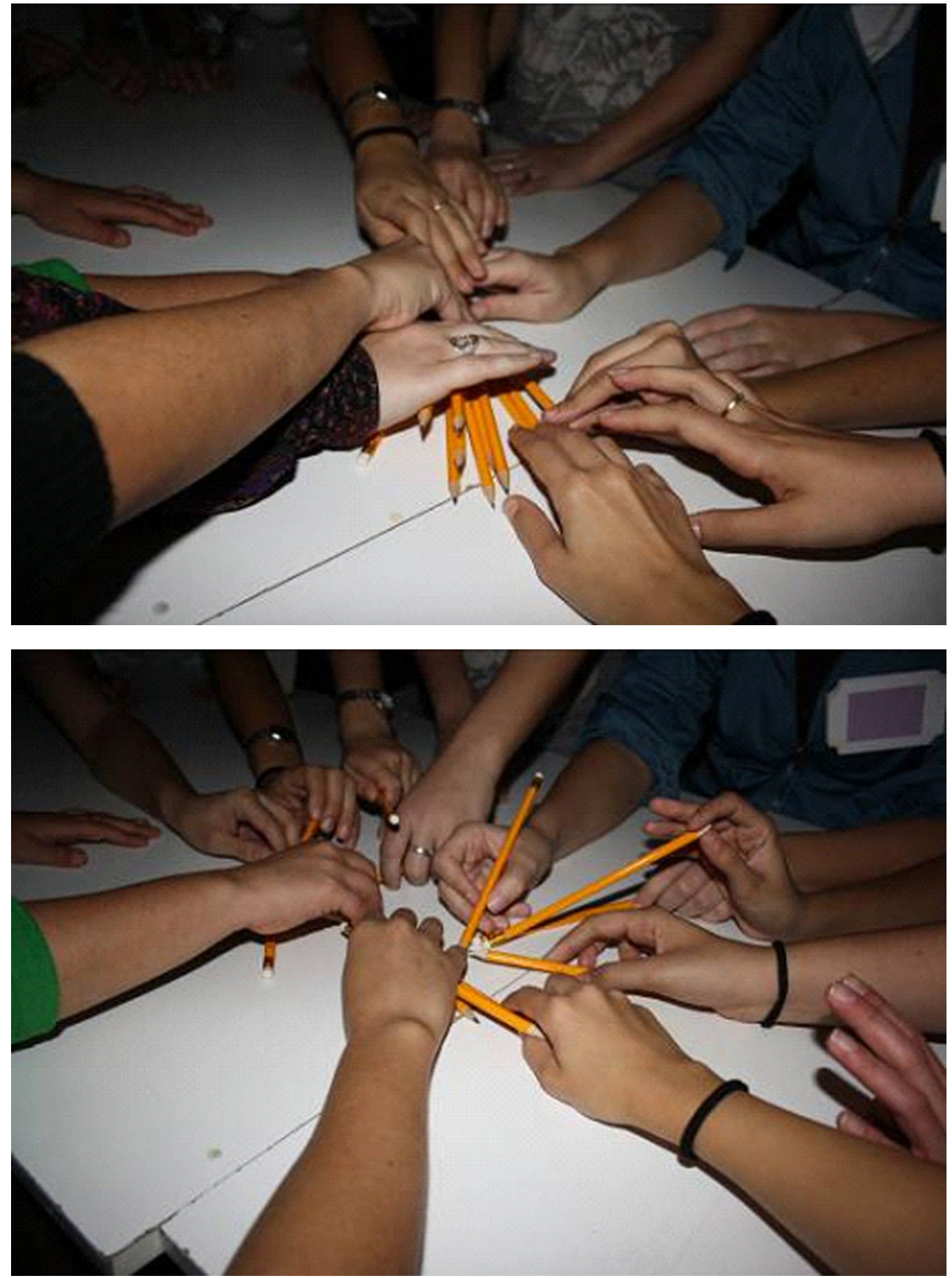

Figura 19. Foto-conclusión. Sesión de elaboración de bocetos. Les pedí que me reglaran una repetición a cámara lenta de esa hermosa danza. 


\section{REFERENCIAS BIBLIOGRÁFICAS}

AGRA, M. J. (2005). El vuelo de la mariposa: la investigación artístico-narrativa como herramienta de formación. En R. Marín (Ed.), Investigación en Educación Artística (pp. 127-150). Granada: Editorial Universidad de.

EISNER, W. E. (2004). El arte y la creación de la mente. El papel de las artes visuales en la transformación de la conciencia. Barcelona: Ediciones Paidós Ibérica (Ed. Orig. 2002).

EISNER, W. E. \& Barone, T. (2006). Arts-Based Educational Research. En J. L. Green, G. Camilli y P. B. Elmore (Eds.), Handbook of complementary methods in education research (pp. 95-109). Mahwah, New Jersey: AERA.

HERNÁNDEZ, F. (2008). La investigación basada en las artes. Propuestas para repensar la investigación en educación. Educatio Siglo XXI, 26, 85-118.

MARÍN, R. (2005). La "Investigación Educativa Basada en las Artes Visuales" o "Arteinvestigación educativa”. En R. Marín (Ed.), Investigación en Educación Artística (pp. 223-274). Granada: Editorial Universidad de.

\section{NOTA:}

Articulo Basado en Tesis doctoral "La formación del alumnado de Magisterio en Educación Artística. Un estudio de caso a partir de las historias de vida de futuros docentes de la Universidad de Alicante", presentada en la Facultad de Magisterio Ausiàs March de la Universitat de València en octubre de 2011 